\title{
Evaluation of some Chemical Substances as Inducers for Tomato Resistance Against Root-Knot Nematode, Meloidogyne incognita
}

\author{
A.A. Anter ${ }^{\star}$, A.W. Amin ${ }^{\star}$, A. H. Ashoub ${ }^{\star *}$ and A.S. El-Nuby \\ *Zoology and Agriculture Nematology Department, Fac. Agric., Cairo University \\ ${ }^{* \star}$ Nematology Unit., Plant Protection Department, Desert Research Center, Cairo. \\ Corresponding author email: aminamin280@gmail.com
}

\begin{abstract}
The potency of the some chemicals from different groups known as inducers of systemic acquired resistance (SAR) viz., acetylsalicylic acid (ASA), DL-3aminobutyric acid (BABA), 2,6-dichloroisonicotinic acid (INA), 5-chlorosalicylic acid (CSA), nitrosalicylic acid (NSA), salicylic acid (SA), ascorbic acid (AS), and selenium (SE) in reducing reproduction Meloidogyne incognita in tomato plants cv. Castel rock was investigated under greenhouse conditions. Supplying chemicals three days-before nematode inoculation showed maximum efficacy in reducing nematode galls, egg-masses and eggs numbers followed by synchronized addition with inoculation, while post-inoculation treatment was less effective. Reiterative doses post-inoculation were improved the efficacy of single dose, also three doses used were more effective than one or two, while, differences between two or three doses were insignificant. On the other hand, plant fitness was slightly impaired with third dose than second one. INA and SE showed pronounced effect in inhibition nematode population after third dose compared with the rest chemicals, which showed mild increase in their efficacy from second to third doses. Unfortunately, three doses of SE were reduced plant fitness after enhanced by double doses, while INA was showed obvious phytotoxicity gradually increased by repeating doses. Gathering between the most effective application time (before inoculation) and the proper activated dose after inoculation was studies for emphasized their action and comparing with pre-inoculation only in suppressing $M$. incognita population. Chemical activators showed enhancing in peroxidase and polyphenoloxidase activities. In conclusion, CSA, NSA, BABA and SA were showed highest efficacy as resistance inducers. This collectively showed reduction of total population with pre-inoculation time application and pre plus post-inoculation application, $57.6 \& 83.8 \%, 56.5 \& 81.6 \%, 55.4 \& 79.2 \%$ and $54.5 \& 78.1 \%$, respectively. Also the fecundity of nematode was taking similar trend as total population. The results suggest that tested chemicals especially CSA, NSA, BABA and SA have potential to suppress root-knot nematode infection in tomato plants through induced systemic resistance.
\end{abstract}

Key words: Induced resistance, chemical inducers, Meloidogyne incognita, tomato. 


\section{Introduction}

Root-knot nematodes, Meloidogyne species are the most important plant parasitic nematodes and wide spread on a wide plant hosts range including agronomic and vegetable crops, ornamental, fruit trees and weeds, especially in tropical and subtropical countries causing economic losses (Amin, 1994). In vegetable crops production, especially tomato in greenhouses, most of the damage from continuous cropping is caused by soil-borne diseases \& nematodes (Molinari and Baser, 2010 and Amin \& Mona, 2014).

Control of nematode is complex and usually demands integrated management practices. The methods most widely used include chemical and biological control and resistant cultivars. However, the use of chemical nematicides, apart from the expenses incurred, can result in chemical residues harmful to humans and the environment as well as selecting for resistant nematodes (Ghini and Kimati, 2000).

Between tomato cultivars few were recorded as resistant to this pest. Genetic control to these important nematode species is limited mainly by the scarcity of high-resistance material by different meaning the lack of resistance for several crops or is present only in wild species or undeveloped genotypes represent a challenge. Resistance is typically a highly specific trait and is effective against only a single or a few nematode species. It may not be durable because of the selection of resistance-breaking populations that render the resistance effective in specific locations (Starr and Roberts, 2004). Other factors are also important, such as restriction to region, climate and nematode species (Franzener et al., 2007).

Consequently, new strategies for the control of plant-parasitic nematodes have actively been sought in the last few years. Investigation has focused on biological control, organic and inorganic amendments, naturally occurring nematicides and induced resistance (Oka et al., 2000). Induction of resistance has attracted the interest of researchers is the use of resistance inducers. Resistance inducers or elicitors can take the form of a chemicals or biotic agents whose function is to activate the plant's defense mechanisms (Baysal et al., 2003; Silva et al., 2004; Bonaldo et al., 2005 and Dias-Arieira et al., 2012). Systemic acquired resistance (SAR) and induced systemic resistance (ISR) are two known ways of inducing plant resistance to disease.

Resistance to pathogens can be chemically induced by applying to plants salicylic acid (SA) and compounds which can mimic the action of SA, such as acibenzolar-S-methyl(ASM) and 2,6-dicholoroisonicotinic acid (INA) (Molinari and Baser, 2010).

In this study, some chemical elicitors have been tested as inducers of resistance to RKNs taking into account the effect of different application times, the 
effect of doses number post-inoculation and the combination between the best time of application and proper number of doses.

\section{Materials and Methods}

Single egg-mass of Meloidogyne incognita was reared on tomato plants cv. Castel rock in $25 \mathrm{~cm}$-diam. earthen pots containing more than one $\mathrm{kg}$ sand clay soil. Six weeks later, nematode second stage juveniles $\left(\mathrm{J}_{2}\right)$ were extracted by allowing egg-masses to hatch in Petri-dishes. Nematode inoculation was done using 1000 freshly hatched juveniles $\left(\mathrm{J}_{2}\right)$ / pot.

Three experiments were carried out in sterilized soil (3:1 sand:clay v: v) in 25 $\mathrm{cm}$-diam. earthen pots. Five-week old tomato seedlings, Lycopersicon esculentum Mill cv. Castel rock were grown in all experiments as susceptible host.

The first experiment (Time of application) was divided into three groups: the first group was received chemicals three day before nematode inoculation, the second group was received chemicals synchronize with inoculation time and the third group was received chemicals three days after inoculation time. One thousand freshly hatched juveniles of $M$. incognita were added per pot (each pot contains one tomato seedling).

Pots soil were drenched by $100 \mathrm{ml}$ distilled sterilized water per plant with either $2.5 \mathrm{mM}$ of acetylsalicylic acid (ASA), salicylic acid (SA) or 5-chlorosalicylic acid (CSA) or with either $1.25 \mathrm{mM}$ nitro salicylic acid (NSA), $20 \mathrm{mM}$ ascorbic acid (AS) or 20 mMDL-3-aminobutyric acid (BABA) or with either $0.62 \mathrm{mM}$ selenium (SE) or $0.25 \mathrm{mM}$ 2.6-dichloroisonicotinic acid (INA). Four untreated inoculated pots were drenched with $100 \mathrm{ml}$ distilled sterilized water left as check treatment. The previous chemicals as the same concentrations were used in the present three experiments.

The second experiment (Effect of reiterative doses) was divided into three groups: the first group was received single dose of chemicals after 7 days from nematode inoculation time, the second group was received two doses of chemicals after 7 and 14 days from nematode inoculation time and third group was received three time of chemicals after 7, 14 and 21 days from nematode inoculation time.

The third experiment was divided into two groups: the first group was received chemicals at 3 days before nematode inoculation time (one dose). The second group was received chemicals at 3 days before nematode inoculation time (first dose) and 7 days after nematode inoculation time (second dose).

The plants under greenhouse were irrigated and fertilized according to the recommendations of the Egyptians Ministry of Agriculture. The treatments were replicated four times (4 pots) in a completely randomized block design. After 45 days of nematode inoculation, roots of plants were carefully uprooted and 
nematodes in soil and roots were counted and recorded based on galls, No. of juveniles in soil, developmental stages, mature female, egg masses numbers per plant and eggs per egg-mass. Reproductive factor (RF) compared to untreated pots was calculated for root-knot nematodes. The data were subjected to analysis of variance and means were separated by the least significant difference LSD at $(p=0.05)$ using PLABSTAT program Version 3.

Enzymes extraction: Enzyme extract were prepared according to Maxwell and Batemen (1967) by grinding the root tissues which were collected from healthy and chemicals treated tomato plants in $0.1 \mu$ sodium phosphate buffer at $\mathrm{pH}$ $7.1(2 \mathrm{ml} / \mathrm{gm}$ fresh plant) for $1 \mathrm{~min}$ at high speed in a small homogenizer. These triturate tissues were strained through four layers of cheese cloth and the filtrates were centrifuged at $1500 \mathrm{~g}$ for $20 \mathrm{~min}$ at $4^{\circ} \mathrm{C}$, the supernatant fluids were used for the enzymes assay.

Changes in peroxidase (POX) activity associated with the different treatments and healthy plants were determined following the procedure described by Sridhar and Ou (1974). Peroxidase activity was expressed as change in absorbance ( $\Delta$ O.D $470 \mathrm{~nm}$ ) per min/gram fresh weight of tomato roots.

Changes in polyphenol oxidase (PPO) activity associated with the different treatments and healthy plants were determined following the procedure described by Maxwell and Batemen (1967). The activity of PPO oxidase was expressed as change in absorbance $(\Delta$ O.D $495 \mathrm{~nm}$ ) $/ 1.0 \mathrm{ml}$ of extract per min per gram fresh weight. Three replicates for each treatment were analyzed to determine of plant enzymes activity. Relative activity percentage compared with healthy tomato plant was calculated, (activity of treated/healthy) $\times 100$, and recorded.

\section{Results}

The results in Table 1 indicated that application of such chemicals (Effect of application time) three days pre-inoculation time was most effective than at or postinoculation time. Moreover, CSA, NSA, BABA and SA were found to be more efficacious chemicals in suppressing $M$. incognita reproduction and developments. According to the previous arrangement, the galls reduction percentages were 89.8, 85.7, 83.7 and 81.6, while egg-masses (EM) reduction percentages recorded 91.1, $88.9,86.7$ and 82.2. The reduction percentages of total eggs deposited by these chemicals were 97.2, 96.2, 95.1 and 93.1 for CSA, NSA, BABA and SA respectively. ASA achieved similar reduction percentage of galls and egg-masses (75.5), while INA achieved (77.6 and 77.8) and total eggs were recorded 87.9 and 89.4. The minimum reduction was registered by SE and AS. At the second treatment, synchronous addition, the most effective chemicals were the same four chemicals. These chemicals occupied a descending order as CSA, NSA, BABA and 
Table (1). Effect of application time on efficacy of certain chemical substances on development and reproduction of Meloidogyne incognita infected tomato roots.

\begin{tabular}{|c|c|c|c|c|c|c|c|c|c|}
\hline \multirow{2}{*}{$\begin{array}{l}\text { Treat- } \\
\text { ments }\end{array}$} & \multirow{2}{*}{$\begin{array}{l}\text { Chemical } \\
\text { substances }\end{array}$} & \multirow{2}{*}{$\begin{array}{l}\text { No. of } \\
\text { Galls }\end{array}$} & \multirow[b]{2}{*}{ *\%R } & \multirow{2}{*}{$\begin{array}{c}\text { No. of } \\
\text { Egg- } \\
\text { masses }\end{array}$} & \multirow[b]{2}{*}{$\% R$} & \multirow{2}{*}{$\begin{array}{c}\text { No. of } \\
\text { Eggs / } \\
\text { egg- mass }\end{array}$} & \multirow[b]{2}{*}{$\% R$} & \multirow{2}{*}{$\begin{array}{l}\text { Total } \\
\text { eggs }\end{array}$} & \multirow[b]{2}{*}{$\% R$} \\
\hline & & & & & & & & & \\
\hline \multirow{10}{*}{ 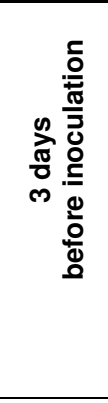 } & Acetyl salicylic acid & 12 & 75.5 & 11 & 75.6 & 206 & 50.4 & 2266 & 87.9 \\
\hline & $\beta$-aminobutyric acid & 8 & 83.7 & 6 & 86.7 & 151 & 63.6 & 906 & 95.1 \\
\hline & Ascorbic acid & 17 & 65.3 & 16 & 64.4 & 275 & 33.7 & 4400 & 76.4 \\
\hline & Chloroisonicotinic acid & 11 & 77.6 & 10 & 77.8 & 198 & 52.3 & 1980 & 89.4 \\
\hline & Chlorosalicylic acid & 5 & 89.8 & 4 & 91.1 & 131 & 68.4 & 524 & 97.2 \\
\hline & Nitro salicylic acid & 7 & 85.7 & 5 & 88.9 & 141 & 66.0 & 705 & 96.2 \\
\hline & Salicylic acid & 9 & 81.6 & 8 & 82.2 & 160 & 61.5 & 1280 & 93.1 \\
\hline & Selenium & 16 & 67.4 & 14 & 68.9 & 232 & 44.1 & 3248 & 82.6 \\
\hline & Control & 49 & - & 45 & - & 415 & - & 18675 & - \\
\hline & Mean time & 14.89 & - & 13.67 & - & 212.1 & - & - & - \\
\hline \multirow{10}{*}{ 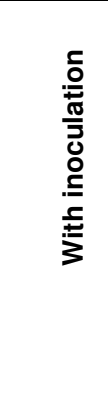 } & Acetyl salicylic acid & 18 & 63.3 & 17 & 62.2 & 249 & 40.0 & 4233 & 77.3 \\
\hline & $\beta$-aminobutyric acid & 13 & 73.5 & 12 & 73.3 & 180 & 56.6 & 2160 & 88.4 \\
\hline & Ascorbic acid & 23 & 53.1 & 22 & 51.1 & 311 & 25.1 & 6842 & 63.4 \\
\hline & Chloroisonicotinic acid & 15 & 69.4 & 15 & 66.7 & 219 & 47.2 & 3285 & 82.4 \\
\hline & Chlorosalicylic acid & 11 & 77.6 & 10 & 77.8 & 149 & 64.1 & 1490 & 92.0 \\
\hline & Nitro salicylic acid & 12 & 75.5 & 11 & 75.6 & 176 & 57.6 & 1936 & 89.6 \\
\hline & Salicylic acid & 14 & 71.4 & 14 & 68.9 & 189 & 54.5 & 2646 & 85.8 \\
\hline & Selenium & 21 & 57.1 & 20 & 55.6 & 258 & 37.8 & 5160 & 72.4 \\
\hline & Control & 49 & - & 45 & - & 415 & - & 18675 & - \\
\hline & Mean time & 19.56 & - & 18.89 & - & 238.4 & - & - & - \\
\hline \multirow{10}{*}{ 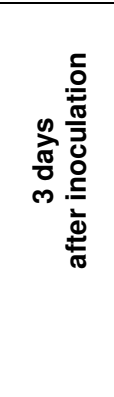 } & Acetyl salicylic acid & 32 & 34.7 & 20 & 55.6 & 339 & 18.3 & 6780 & 63.7 \\
\hline & $\beta$-aminobutyric acid & 25 & 49.0 & 15 & 66.7 & 220 & 47.1 & 3300 & 82.3 \\
\hline & Ascorbic acid & 38 & 22.5 & 26 & 42.2 & 374 & 9.9 & 9724 & 47.9 \\
\hline & Chloroisonicotinic acid & 31 & 36.7 & 19 & 57.8 & 320 & 22.9 & 6080 & 67.4 \\
\hline & Chlorosalicylic acid & 22 & 55.1 & 13 & 71.1 & 182 & 56.1 & 2366 & 87.3 \\
\hline & Nitro salicylic acid & 23 & 53.1 & 14 & 68.9 & 212 & 48.9 & 2968 & 84.1 \\
\hline & Salicylic acid & 26 & 46.9 & 17 & 62.2 & 227 & 45.3 & 3859 & 79.3 \\
\hline & Selenium & 34 & 30.6 & 24 & 46.7 & 357 & 14.0 & 8568 & 54.1 \\
\hline & Control & 49 & - & 45 & - & 415 & - & 18675 & - \\
\hline & Mean time & 31.11 & - & 21.44 & - & 294.0 & - & - & - \\
\hline \multirow{8}{*}{ 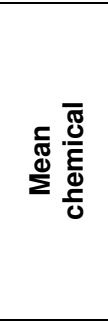 } & Acetyl salicylic acid & 20.7 & - & 16.0 & - & 264.7 & - & - & - \\
\hline & $\beta$-aminobutyric acid & 15.3 & - & 11.0 & - & 183.7 & - & - & - \\
\hline & Ascorbic acid & 26.0 & - & 21.3 & - & 320.0 & - & - & - \\
\hline & Chloroisonicotinic acid & 19.0 & - & 14.7 & - & 245.7 & - & - & - \\
\hline & Chlorosalicylic acid & 12.7 & - & 9.0 & - & 154.0 & - & - & - \\
\hline & Nitro salicylic acid & 14.0 & - & 10.0 & - & 176.3 & - & - & - \\
\hline & Salicylic acid & 16.3 & - & 13.0 & - & 192.0 & - & - & - \\
\hline & Selenium & 23.7 & - & 19.3 & - & 282.3 & - & - & - \\
\hline \multicolumn{2}{|c|}{ LSD 0.05 Chemicals } & 1.41 & & 1.12 & & 10.04 & & & \\
\hline \multicolumn{2}{|c|}{ LSD 0.05 Time } & 1.10 & & 0.79 & & 0.83 & & & \\
\hline \multicolumn{2}{|c|}{ LSD 0.05 CxT } & 2.45 & & 1.95 & & 17.39 & & & \\
\hline
\end{tabular}

*\%R= Reduction percentage. 
SA, respectively according to galls formation, egg-masses production and total population reduction percentages. The lowest efficacy was related to AS (Table 1). Application of chemicals three days after nematode inoculation was recorded the same positions in the previous treatments and with the same descending order. SE treatment could be considered as the less effective inducer for suppressing nematode population Table 1.

Results listed in Table 2 showed an enhancement of tested chemicals efficacy at post-inoculation by repeating doses. Chlorosalicylic acid (CSA) had the highest ability to suppress the formation of galls to 95 galls and the production of eggmasses (EM) to $59 \mathrm{EM} /$ plant compared to untreated control plant as one dose after inoculation, which formed 232 galls/plant and produce $143 \mathrm{EM} /$ plant. On the other side, SE had the lowest capability to inhibit galls formation and egg-masses production where they recorded 165 galls and $119 \mathrm{EM} /$ plant. The rested chemicals could rank in descending order according to their ability to diminish galls formation as nitrosalicylic acid (NSA)> $\beta$-aminobutyric acid (BABA) > salicylic acid (SA)> 2,6dichloroisonicotinic acid (INA)> acetylsalicylic acid (ASA) > ascorbic acid (AS).

Concerning the second treatment, two doses, the highest effect that cease $M$. incognita galls formation was in combine with both CSA (41) and NSA (42) compared to control which formed 232 galls/plant. The feeblest effect showed by AS where it formed 150 galls/plant. The production of egg-masses took similar trend where CSA and NSA suppress EM/plant to 40 and 44 respectively. Moderate effects were related to BABA, SA and INA which produced 53, 59 and 63 respectively, while SE gave $94 \mathrm{EM} /$ plant as a lesser effective chemical. The highest total population reduction was related to CSA (72.7\%), NSA (70.4\%), BABA (65.6\%) and SA (62.5\%). While the lowest reduction was 42.7 and $41.9 \%$ induced by SE and $A S$.

Regarding to the third treatment, three doses, there were three chemicals which could minimize gall formation; INA, SE and NSA where they recorded 34, 36 and 39 galls/plant. While the maximum gall formation was related to AS (130) compared to untreated control. INA stills the highest effective chemical on inhibiting $\mathrm{EM} /$ plant formation which recorded $15 \mathrm{EM} /$ plant. Furthermore, AS still the lesser effective chemical where it gave 72 compared to control (143 EM/plant).

Data in presented in Table 3 showed that all chemicals with different doses encouraged plant growth criteria except INA whereas it induced decrement in weight of both shoot and root under the different doses (Fig. 1).

The efficacy of one application pre-inoculation $(\mathrm{P})$ and two applications pre and post-inoculation with nematode (P.P) were tested, where this combination aims to increase the effectiveness of such chemical substance in field application (Table 4). The double application (P.P) maximized the ability of such chemical substance to 
Table (2). Effect of post-inoculation reiterative doses of certain chemical substances on Meloidogyne incognita development and reproduction infected tomato roots.

\begin{tabular}{|c|c|c|c|c|c|c|c|c|}
\hline \multirow[b]{2}{*}{ Treatments } & \multirow{2}{*}{$\begin{array}{l}\text { Chemical } \\
\text { substances }\end{array}$} & \multicolumn{4}{|c|}{ Number of } & \multirow[b]{2}{*}{ TP } & \multirow[b]{2}{*}{$\%$ TPR $^{*}$} & \multirow{2}{*}{$\begin{array}{l}\text { Eggs } \\
\text { / egg- } \\
\text { mass }\end{array}$} \\
\hline & & Galls & $\begin{array}{l}\text { Devel. } \\
\text { stages }\end{array}$ & Females & $\begin{array}{l}\text { Egg- } \\
\text { masses }\end{array}$ & & & \\
\hline \multirow{10}{*}{ 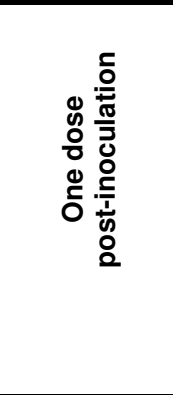 } & Acetyl salicylic acid & 152 & 57 & 146 & 116 & 203 & 19.8 & 216 \\
\hline & $\beta$-aminobutyric acid & 126 & 34 & 110 & 87 & 144 & 43.1 & 188 \\
\hline & Ascorbic acid & 167 & 74 & 153 & 122 & 227 & 10.3 & 232 \\
\hline & Chloroisonicotinic acid & 147 & 51 & 123 & 104 & 174 & 31.2 & 210 \\
\hline & Chlorosalicylic acid & 95 & 30 & 75 & 59 & 105 & 58.5 & 138 \\
\hline & Nitro salicylic acid & 104 & 36 & 82 & 63 & 118 & 53.4 & 173 \\
\hline & Salicylic acid & 144 & 45 & 126 & 98 & 171 & 32.4 & 198 \\
\hline & Selenium & 165 & 58 & 151 & 119 & 209 & 17.4 & 230 \\
\hline & Control & 232 & 75 & 178 & 143 & 253 & - & 266 \\
\hline & Mean dose & 148.0 & 51.1 & 127.1 & 101.2 & - & - & 205.7 \\
\hline \multirow{10}{*}{ 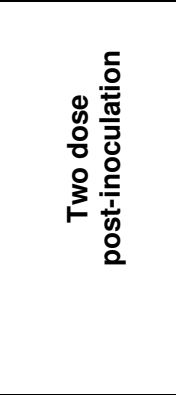 } & Acetyl salicylic acid & 89 & 27 & 101 & 81 & 128 & 49.4 & 176 \\
\hline & $\beta$-aminobutyric acid & 60 & 19 & 68 & 53 & 87 & 65.6 & 115 \\
\hline & Ascorbic acid & 150 & 41 & 106 & 84 & 147 & 41.9 & 221 \\
\hline & Chloroisonicotinic acid & 79 & 22 & 78 & 63 & 100 & 60.5 & 161 \\
\hline & Chlorosalicylic acid & 41 & 15 & 54 & 40 & 69 & 72.7 & 94 \\
\hline & Nitro salicylic acid & 42 & 17 & 58 & 44 & 75 & 70.4 & 104 \\
\hline & Salicylic acid & 79 & 20 & 75 & 59 & 95 & 62.5 & 118 \\
\hline & Selenium & 91 & 31 & 114 & 94 & 145 & 42.7 & 223 \\
\hline & Control & 232 & 75 & 178 & 143 & 253 & - & 266 \\
\hline & Mean dose & 95.9 & 29.7 & 92.4 & 73.4 & - & - & 165.3 \\
\hline \multirow{10}{*}{ 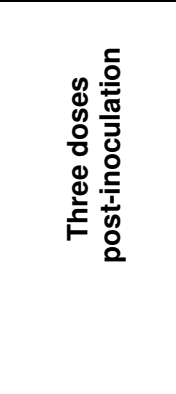 } & Acetyl salicylic acid & 85 & 13 & 84 & 65 & 97 & 61.7 & 169 \\
\hline & $\beta$-aminobutyric acid & 58 & 12 & 52 & 39 & 64 & 74.7 & 103 \\
\hline & Ascorbic acid & 130 & 14 & 95 & 72 & 109 & 56.9 & 192 \\
\hline & Chloroisonicotinic acid & 34 & 4 & 25 & 15 & 29 & 88.5 & 54 \\
\hline & Chlorosalicylic acid & 46 & 8 & 44 & 33 & 52 & 79.4 & 62 \\
\hline & Nitro salicylic acid & 39 & 9 & 47 & 35 & 56 & 77.9 & 84 \\
\hline & Salicylic acid & 77 & 13 & 69 & 55 & 82 & 67.6 & 105 \\
\hline & Selenium & 36 & 7 & 45 & 26 & 52 & 79.4 & 90 \\
\hline & Control & 232 & 75 & 178 & 143 & 253 & - & 266 \\
\hline & Mean dose & 81.9 & 17.2 & 71.0 & 53.7 & - & - & 125.0 \\
\hline \multirow{8}{*}{ 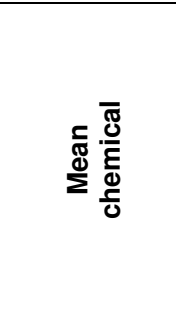 } & Acetyl salicylic acid & 108.6 & 32.3 & 110.3 & 87.3 & - & - & 187.0 \\
\hline & -aminobutyric acid $\beta$ & 81.3 & 21.7 & 76.7 & 59.7 & - & - & 135.3 \\
\hline & Ascorbic acid & 149.0 & 43.0 & 118.0 & 92.7 & - & - & 215.0 \\
\hline & Chloroisonicotinic acid & 86.7 & 25.7 & 75.3 & 60.7 & - & - & 141.7 \\
\hline & Chlorosalicylic acid & 60.7 & 17.7 & 57.7 & 44.0 & - & - & 98.0 \\
\hline & Nitro salicylic acid & 61.7 & 20.7 & 62.3 & 47.3 & - & - & 120.3 \\
\hline & Salicylic acid & 100.0 & 26.0 & 90.0 & 70.7 & - & - & 140.3 \\
\hline & Selenium & 97.3 & 32.0 & 103.3 & 79.7 & - & - & 184.3 \\
\hline \multicolumn{2}{|c|}{ LSD 0.05 Chemicals (C) } & 8.45 & 2.95 & 3.40 & 5.61 & & & 6.94 \\
\hline \multicolumn{2}{|c|}{ LSD 0.05 Doses (D) } & 6.08 & 2.11 & 3.10 & 3.49 & & & 3.61 \\
\hline \multicolumn{2}{|c|}{ LSD 0.05 CxD } & 14.63 & 5.12 & 10.23 & 9.72 & & & 12.01 \\
\hline
\end{tabular}

*\%TPR = Total population Reduction. 
Table (3). Effect of reiterative doses of certain chemicals on growth responses of tomato plants infected by Meloidogyne incognita.

\begin{tabular}{|c|c|c|c|c|c|c|}
\hline Doses & Chemical substances & $\begin{array}{l}\text { Fresh } \\
\text { shoot } \\
\text { weight }\end{array}$ & $\begin{array}{c}\text { Dry } \\
\text { shoot } \\
\text { weight }\end{array}$ & $\begin{array}{l}\text { Shoot } \\
\text { length }\end{array}$ & $\begin{array}{c}\text { Root } \\
\text { weight }\end{array}$ & $\begin{array}{l}\text { Root } \\
\text { length }\end{array}$ \\
\hline \multirow{10}{*}{ 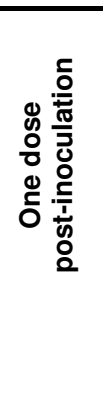 } & Acetyl salicylic acid & 6.6 & 1.5 & 26.3 & 2.7 & 28.6 \\
\hline & $\beta$-aminobutyric acid & 7.5 & 1.6 & 30.7 & 3.6 & 24.6 \\
\hline & Ascorbic acid & 7.6 & 1.5 & 26.7 & 3.9 & 24.6 \\
\hline & Chloroisonicotinic acid & 4.7 & 1.2 & 27.3 & 2.0 & 23.0 \\
\hline & Chlorosalicylic acid & 8.8 & 1.6 & 31.7 & 3.6 & 28.3 \\
\hline & Nitro salicylic acid & 6.4 & 1.3 & 28.0 & 2.3 & 26.0 \\
\hline & Salicylic acid & 5.7 & 1.3 & 27.3 & 2.7 & 23.6 \\
\hline & Selenium & 6.1 & 1.3 & 26.3 & 2.3 & 25.6 \\
\hline & Control & 5.1 & 1.3 & 26.0 & 2.3 & 21.6 \\
\hline & Mean dose & 6.50 & 1.41 & 27.81 & 2.82 & 25.10 \\
\hline \multirow{10}{*}{ 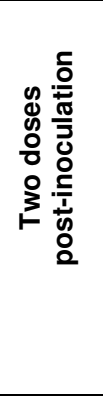 } & Acetyl salicylic acid & 11.9 & 2.1 & 37.0 & 5.7 & 34.0 \\
\hline & $\beta$-aminobutyric acid & 13.4 & 2.3 & 35.3 & 6.5 & 31.0 \\
\hline & Ascorbic acid & 12.9 & 1.9 & 32.7 & 5.6 & 29.0 \\
\hline & Chloroisonicotinic acid & 2.8 & 1.2 & 27.0 & 1.9 & 22.6 \\
\hline & Chlorosalicylic acid & 10.8 & 2.0 & 35.0 & 5.1 & 30.3 \\
\hline & Nitro salicylic acid & 7.5 & 1.7 & 34.7 & 5.5 & 32.3 \\
\hline & Salicylic acid & 8.6 & 2.0 & 36.7 & 4.7 & 31.6 \\
\hline & Selenium & 9.6 & 1.9 & 32.0 & 5.4 & 30.3 \\
\hline & Control & 5.1 & 1.3 & 26.0 & 2.3 & 21.6 \\
\hline & Mean dose & 9.17 & 1.82 & 32.92 & 4.75 & 29.19 \\
\hline \multirow{10}{*}{ 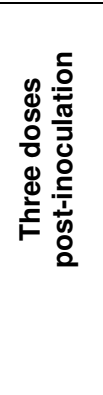 } & Acetyl salicylic acid & 9.7 & 1.9 & 27.7 & 5.3 & 31.6 \\
\hline & $\beta$-aminobutyric acid & 10.3 & 1.9 & 33.0 & 3.5 & 29.0 \\
\hline & Ascorbic acid & 6.9 & 1.4 & 31.3 & 3.5 & 29.0 \\
\hline & Chloroisonicotinic acid & 2.6 & 1.2 & 26.3 & 1.7 & 22.0 \\
\hline & Chlorosalicylic acid & 10.1 & 1.9 & 32.3 & 5.0 & 29.3 \\
\hline & Nitro salicylic acid & 6.5 & 1.4 & 31.7 & 3.8 & 27.7 \\
\hline & Salicylic acid & 6.1 & 1.3 & 26.7 & 3.5 & 27.0 \\
\hline & Selenium & 7.0 & 1.5 & 28.7 & 2.4 & 29.3 \\
\hline & Control & 5.1 & 1.3 & 26.0 & 2.3 & 21.6 \\
\hline & Mean dose & 7.15 & 1.50 & 29.29 & 3.44 & 27.39 \\
\hline \multirow{11}{*}{ 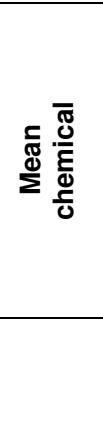 } & Acetyl salicylic acid & 9.41 & 1.84 & 30.33 & 4.59 & 31.40 \\
\hline & $\beta$-aminobutyric acid & 10.41 & 1.91 & 33.00 & 4.50 & 28.22 \\
\hline & Ascorbic acid & 9.13 & 1.61 & 30.22 & 4.31 & 27.55 \\
\hline & Chloroisonicotinic acid & 3.35 & 1.20 & 26.89 & 1.90 & 22.53 \\
\hline & Chlorosalicylic acid & 9.90 & 1.83 & 33.00 & 4.56 & 29.30 \\
\hline & Nitro salicylic acid & 6.81 & 1.46 & 31.44 & 3.88 & 28.66 \\
\hline & Salicylic acid & 6.78 & 1.54 & 30.22 & 3.64 & 27.40 \\
\hline & Selenium & 7.54 & 1.57 & 29.00 & 3.38 & 28.41 \\
\hline & LSD 0.05 Chemicals(C) & 0.50 & 0.08 & 1.74 & 0.18 & 1.38 \\
\hline & LSD 0.05 Doses(D) & 0.33 & 0.05 & 1.28 & 0.14 & 1.32 \\
\hline & LSD 0.05 CxD & 0.87 & 0.14 & 3.01 & 0.31 & 2.39 \\
\hline
\end{tabular}


Fig. (1): Effect of post-inoculation reiterative doses of certain chemicals on increment percentage of tomato growth parameters infected by $M$. incognita.

(A)

口One dose $\square$ Two doses $\square$ Three doses

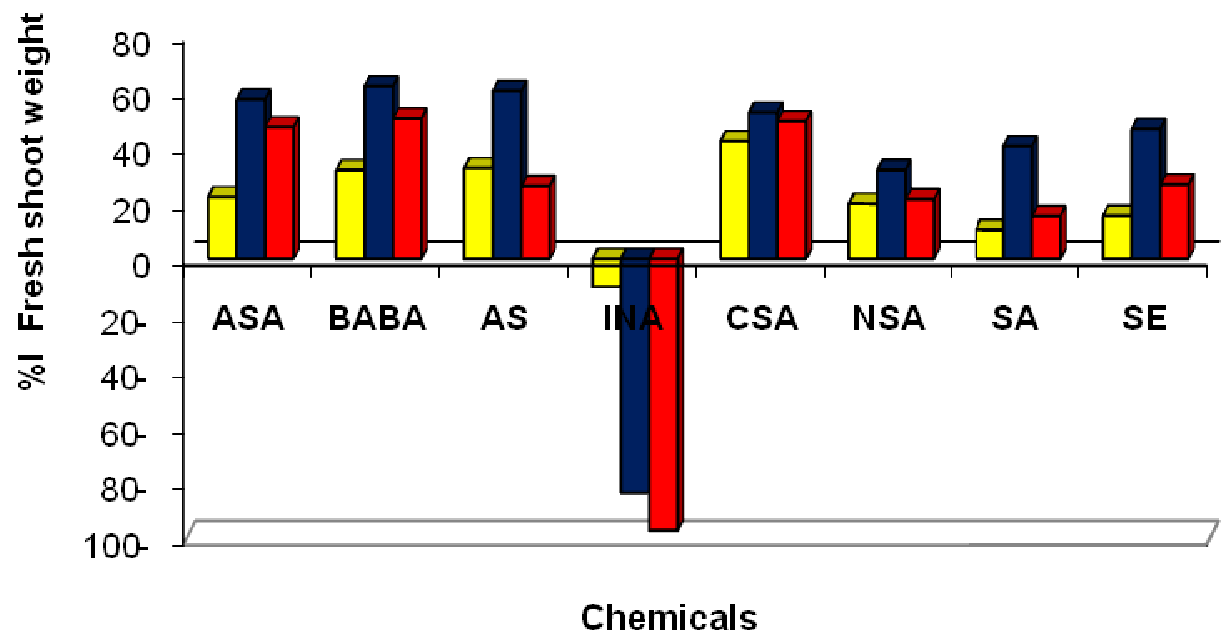

(B)

口Onedose aTwodoses aThreedoses

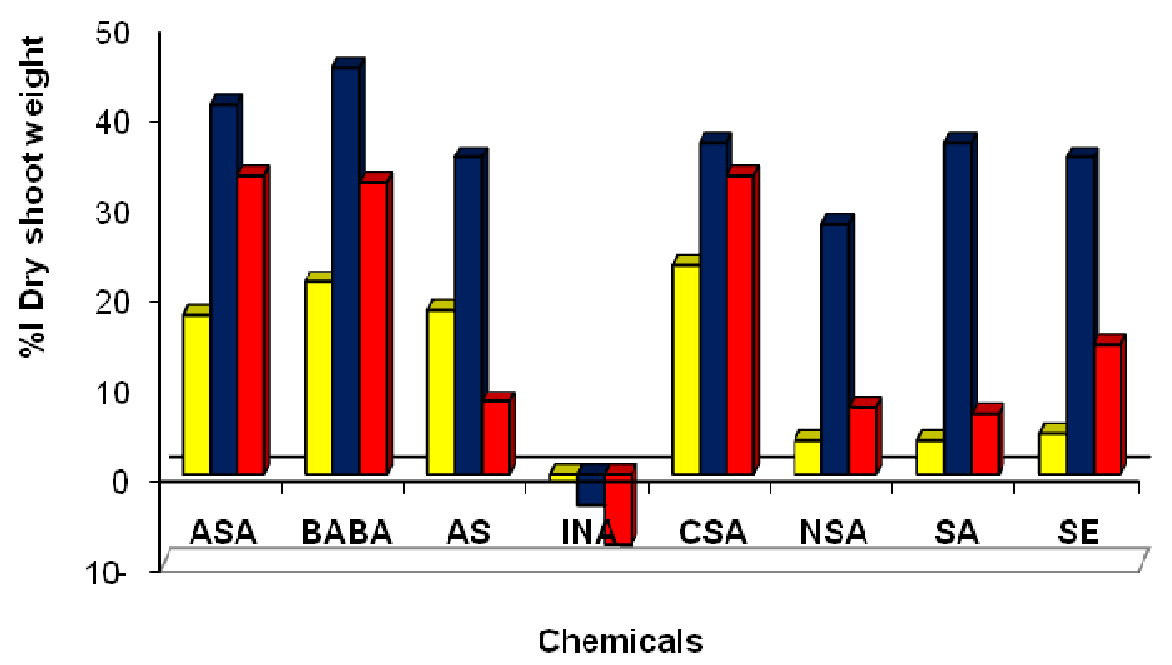

Continue 
Fig. (1): Cont.

(C)

口Onedose $\square$ Two doses aThree doses

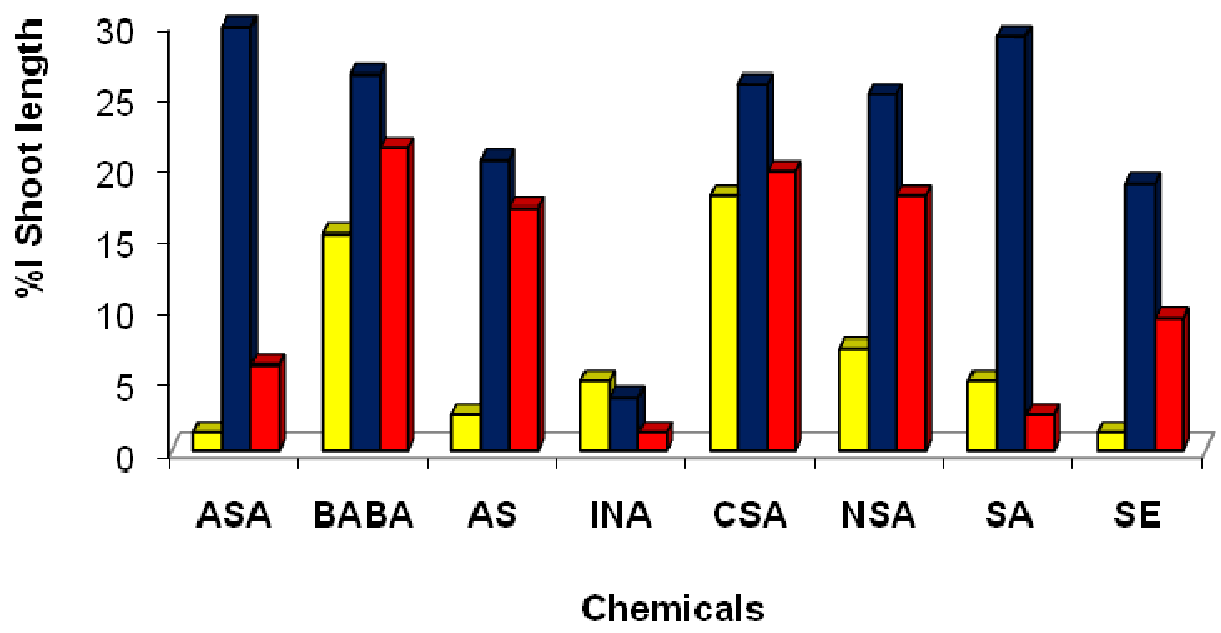

(D)

口One dose $\square$ Two doses $\square$ Three doses

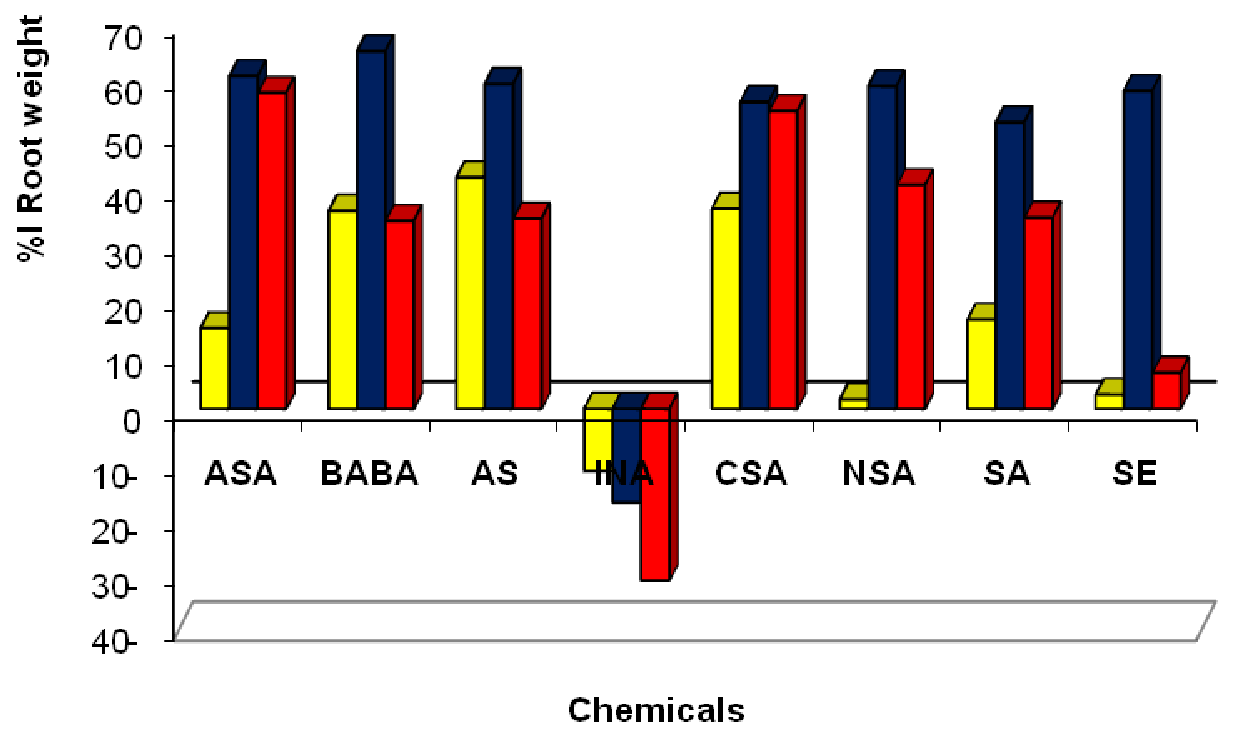

$\mathrm{ASA}=\mathrm{Acetylsalicylic}$ acid, $\mathrm{BABA}=\beta$-aminobutyric acid, $\mathrm{AS}=\mathrm{Ascorbic}$ acid, $\mathrm{CSA}=$ Chlorosalicylic acid, INA= Chloroisonicotinic acid $S A=$ Salicylic acid, $N S A=$ Nitrosalicylic acid, $S E=$ Selenium. 
suppress nematode infection and reproduction. Thus, galls/plant formation by CSA and NSA were diminished to 112 and 116 respectively, while the same chemicals with (P) application minimized the galls to 151 and 158 consecutively. Concerning AS which gave the highest galls number (296) in (P) application comparing to untreated control, that permit to form 422, itself gave 273 with (P.P) as the highest value. However, it was noted that all tested chemicals exhibited high efficacy when the chemical applied pre and post nematode inoculation compared with preapplication only. The egg-masses/plant production confirmed the same previous trend, where as, pre and post-applications was more successful than preapplication only. Besides, both of CSA and NSA achieved the most suppressive effect, where they could decrease egg-masses production to 102 and 111 in succession with (P.P) application while these values increased to 161 and 167 order to with $(P)$ application. The maximum egg-masses production (247) was induced by SE with $(P)$ comparing to control treatment that recorded 382, but the increment with (P.P) was lesser where SE registered $238 \mathrm{EM} /$ plant. Total population reduction was maximized by the same chemicals CSA and NSA which presented 84.0 and $81.8 \%$ under (P.P) facing to 57.6 and $56.5 \%$ with $(P)$ application. On the other side, AS registered the lowest reduction as well as 35.1 and $25.7 \%$ respectively.

The plant growth parameters were positively affected by addition of tested chemical both pre (p) or pre and post (P.P) nematode inoculation with $M$. incognita except with INA (Table 5). Concerning plant shoots, salicylic acid (SA) maximized both of fresh and dry weight for P or P.P application, however the P.P treatment was more effective where it recorded 40.5 (P.P), 31.7 (P) and 5.5 (P.P), 4.7 (P) gm for fresh and dry weight, respectively. Also $S A$ gave the highest length as $47.3 \mathrm{~cm}$ with the P.P treatment, while ASA registered the maximum shoot length $(43 \mathrm{~cm})$ with $(P)$. Root weight was maximized by ASA (13.12 gm) without significant differences between it and SA (12.7gm) or CSA (12.27 gm.) with pre and post treatment.

Data in Table 6 showed that activity of two enzymes was elevated in chemically-treated tomato plants. The maximum activity of peroxidase was related to the treatment of CSA, (2.916) and the minimum activity was recorded by SE (0.898) compared to the untreated and inoculated control $(0.782)$, while, the healthy plant registered (0.338). The rest chemicals were arranged according to their ability to enhance POX activity in descending order as follow: NSA, BABA, SA, INA, ASA, AS respectively. CSA substance maximized the activity of polyphenol oxidase enzyme (2.027), and SE is the substance that minimizes the activity of this enzyme (0.560) compared to the infected and untreated control $(0.204)$ and the healthy plant (0.107). On the other hand, the other chemicals could rank in descending order similar to with POX. 
Table (4). Effect of pre and post-inoculation application of chemical substances on Meloidogyne incognita development and reproduction infected with tomato plants under greenhouse conditions.

\begin{tabular}{|c|c|c|c|c|c|c|c|c|c|c|c|c|}
\hline \multirow{2}{*}{ Chemical substances } & \multicolumn{2}{|c|}{ Juveniles in soil } & \multirow{2}{*}{$\begin{array}{c}\text { Mean } \\
\text { C }\end{array}$} & \multicolumn{2}{|c|}{$\begin{array}{c}\text { Developmental } \\
\text { stages }\end{array}$} & \multirow{2}{*}{$\begin{array}{c}\text { Mean } \\
\text { C }\end{array}$} & \multicolumn{2}{|c|}{ Mature females } & \multirow{2}{*}{$\begin{array}{c}\text { Mean } \\
\text { C }\end{array}$} & \multicolumn{2}{|c|}{ Egg masses } & \multirow{2}{*}{ Mean C } \\
\hline & Pre $^{*}$ & $\begin{array}{c}\text { Pot } \\
\text { Post- }\end{array}$ & & Pre- & $\begin{array}{c}P \\
\text { Post- }\end{array}$ & & Pre- & $\begin{array}{c}\mathrm{P} \\
\text { Post- }\end{array}$ & & Pre- & $\begin{array}{c}\mathrm{P} \\
\text { Post- }\end{array}$ & \\
\hline Acetyl salicylic acid & $\begin{array}{l}13942 \\
(30.5)\end{array}$ & $\begin{array}{l}11995 \\
(40.2)\end{array}$ & 12968.5 & $\begin{array}{c}128 \\
(32.5)\end{array}$ & $\begin{array}{c}74 \\
(60.7)\end{array}$ & 101 & $\begin{array}{c}246 \\
(41.7)\end{array}$ & $\begin{array}{c}220 \\
(51.7)\end{array}$ & 233 & $\begin{array}{c}234 \\
(38.7)\end{array}$ & $\begin{array}{c}210 \\
(45.0)\end{array}$ & 222 \\
\hline R-aminobutyric acid & $\begin{array}{l}8928 \\
(55.5)\end{array}$ & $\begin{array}{r}4073 \\
(79.7)\end{array}$ & 6500.5 & $\begin{array}{l}80 \\
(57.5)\end{array}$ & $\begin{array}{c}50 \\
(73.4)\end{array}$ & 65 & $\begin{array}{c}189 \\
(53.3)\end{array}$ & $\begin{array}{c}130 \\
(63.3)\end{array}$ & 159.5 & $\begin{array}{c}180 \\
(52.9)\end{array}$ & $\begin{array}{c}123 \\
(67.8)\end{array}$ & 151.5 \\
\hline Ascorbic acid & $\begin{array}{l}14893 \\
(25.7)\end{array}$ & $\begin{array}{l}13062 \\
(34.9)\end{array}$ & 13977.5 & $\begin{array}{c}144 \\
(23.8)\end{array}$ & $\begin{array}{l}102 \\
(45.9)\end{array}$ & 123 & $(298)$ & $\begin{array}{l}231 \\
(40.0)\end{array}$ & 264.5 & $\begin{array}{l}285 \\
(25.3)\end{array}$ & $\begin{array}{c}219 \\
(42.7)\end{array}$ & 252 \\
\hline Chloroisonicotinic acid & $\begin{array}{l}9742 \\
(51.4)\end{array}$ & $\begin{array}{l}4891 \\
(75.6)\end{array}$ & 7316.5 & $\begin{array}{c}117 \\
(37.9)\end{array}$ & $(67.0)$ & 89.5 & $\begin{array}{c}228 \\
(45.0)\end{array}$ & $\begin{array}{c}167 \\
(55.0)\end{array}$ & 197.5 & $\begin{array}{c}217 \\
(43.3)\end{array}$ & $\begin{array}{c}158 \\
(58.6)\end{array}$ & 187.5 \\
\hline Chlorosalicylic acid & $\begin{array}{l}8517 \\
(57.5)\end{array}$ & $\begin{array}{l}3152 \\
(84.3)\end{array}$ & 5834.5 & $\begin{array}{c}69 \\
(63.7)\end{array}$ & $\begin{array}{c}41 \\
(78.5)\end{array}$ & 55 & $\begin{array}{r}168 \\
(68.7)\end{array}$ & $\begin{array}{c}108 \\
(70.0)\end{array}$ & 138 & $\begin{array}{c}161 \\
(57.8)\end{array}$ & $\begin{array}{c}102 \\
(73.2)\end{array}$ & 131.5 \\
\hline Nitro salicylic acid & $\begin{array}{l}8733 \\
(56.5)\end{array}$ & $\begin{array}{l}3591 \\
(82.1)\end{array}$ & 6162 & $\begin{array}{c}72 \\
(61.7)\end{array}$ & $\begin{array}{c}47 \\
(75.3)\end{array}$ & 59.5 & $\begin{array}{c}176 \\
(56.7)\end{array}$ & $\begin{array}{c}118 \\
(65.0)\end{array}$ & 147 & $\begin{array}{c}167 \\
(56.3)\end{array}$ & $\begin{array}{c}111 \\
(71.0)\end{array}$ & 139 \\
\hline Salicylic acid & $\begin{array}{l}9103 \\
(54.6) \\
(1427\end{array}$ & $\begin{array}{r}4268 \\
(78.7)\end{array}$ & 6685.5 & $\begin{array}{c}87 \\
(54.0)\end{array}$ & $\begin{array}{c}52 \\
(72.3)\end{array}$ & 69.5 & $\begin{array}{c}197 \\
(50.0)\end{array}$ & $\begin{array}{c}148 \\
(60.0)\end{array}$ & 172.5 & $\begin{array}{c}187 \\
(51.1)\end{array}$ & $\begin{array}{c}140 \\
(83.4)\end{array}$ & 163.5 \\
\hline Selenium & $\begin{array}{l}13427 \\
(33.1)\end{array}$ & $\begin{array}{l}12469 \\
(37.8)\end{array}$ & 12948 & $\begin{array}{c}130 \\
(31.0)\end{array}$ & $\begin{array}{c}79 \\
(58.4)\end{array}$ & 104.5 & $\begin{array}{c}259 \\
(38.3)\end{array}$ & $\begin{array}{c}249 \\
(48.3)\end{array}$ & 254 & $\begin{array}{c}247 \\
(35.3)\end{array}$ & $\begin{array}{l}238 \\
(37.6)\end{array}$ & 242.5 \\
\hline Control & \multicolumn{2}{|c|}{20055} & - & \multicolumn{2}{|c|}{189} & - & \multicolumn{2}{|c|}{402} & - & \multicolumn{2}{|c|}{382} & - \\
\hline Mean Time & 11926.7 & 8617.3 & - & 112.9 & 77.3 & - & 240.3 & 197 & - & 228.9 & 187 & - \\
\hline LDS 0.05 Chemicals (C) & 729.57 & & & 4.83 & & & 9.94 & & & 9.63 & & \\
\hline LDS 0.05 Time (T) & 858.78 & & & 3.52 & & & 6.66 & & & 6.39 & & \\
\hline LDS 0.05 CxT & 1031.7 & & & 6.83 & & & 14.08 & & & 13.62 & & \\
\hline
\end{tabular}


Table (4). Cont.

\begin{tabular}{|c|c|c|c|c|c|c|c|c|c|c|c|c|}
\hline \multirow[b]{2}{*}{ Chemical substances } & \multicolumn{2}{|c|}{ Galls } & \multirow{2}{*}{$\begin{array}{c}\text { Mean } \\
\text { C }\end{array}$} & \multicolumn{2}{|c|}{ Eggs/eggmass } & \multirow{2}{*}{$\begin{array}{c}\text { Mean } \\
\text { C }\end{array}$} & \multicolumn{2}{|c|}{ Total population } & \multirow{2}{*}{$\begin{array}{l}\text { \%R } \\
\text { Pre- }\end{array}$} & \multirow{2}{*}{$\begin{array}{c}\mathscr{G R} \\
P \\
\text { Post- }\end{array}$} & \multicolumn{2}{|c|}{$\begin{array}{l}\text { Reproduction } \\
\text { factor }\end{array}$} \\
\hline & Pre- & $\begin{array}{c}P \\
\text { Post- } \\
\end{array}$ & & Pre- & $\begin{array}{c}P \\
\text { Post- }\end{array}$ & & Pre- & P.P & & & Pre- & $\begin{array}{c}P \\
\text { Post- }\end{array}$ \\
\hline A cetyl salicylic acid & $\begin{array}{c}259 \\
(38.6)\end{array}$ & $\begin{array}{c}230 \\
(45.6)\end{array}$ & 244.5 & $\begin{array}{c}385 \\
(36.2)\end{array}$ & $\begin{array}{c}329 \\
(42.5)\end{array}$ & 347 & 14316 & 12289 & 30.68 & 40.48 & 14.31 & 12.28 \\
\hline$\beta$-aminobutyric acid & $\begin{array}{c}169 \\
(59.9)\end{array}$ & $\begin{array}{l}142 \\
(86.3)\end{array}$ & 155.5 & $\begin{array}{l}287 \\
(49.9)\end{array}$ & $\begin{array}{l}244 \\
(57.3)\end{array}$ & 265.5 & 9197 & 4253 & 55.45 & 79.40 & 9.19 & 4.25 \\
\hline A scorbic acid & $\begin{array}{l}296 \\
(29.9)\end{array}$ & $\begin{array}{l}273 \\
(35.2)\end{array}$ & 284.5 & $\begin{array}{l}415 \\
(27.5)\end{array}$ & $\begin{array}{c}379 \\
(33.7)\end{array}$ & 397 & 15335 & 13395 & 25.72 & 35.12 & 15.33 & 13.39 \\
\hline Chloroisonicotinic acid & $\begin{array}{c}220^{\circ} \\
(48.0)\end{array}$ & $\begin{array}{l}194 \\
(54.1)\end{array}$ & 207 & $\begin{array}{l}346 \\
(39.5)\end{array}$ & $\begin{array}{c}314 \\
(45.1)\end{array}$ & 330 & 10087 & 5120 & 51.14 & 75.20 & 10.08 & 5.12 \\
\hline Chlorosalicylic acid & $\begin{array}{c}151 \\
(64.3) \\
(158\end{array}$ & $\begin{array}{c}112 \\
(73.5)\end{array}$ & 131.5 & $\begin{array}{l}277 \\
(51.6)\end{array}$ & $\begin{array}{c}212 \\
(63,3)\end{array}$ & 244.5 & 8754 & 3301 & 57.60 & 84.01 & 8.75 & 3.30 \\
\hline Nitro salicylic acid & $\begin{array}{c}158 \\
(62.6)\end{array}$ & $\begin{array}{c}116 \\
(72.5)\end{array}$ & 137 & $\begin{array}{c}283 \\
(50.5)\end{array}$ & $\begin{array}{l}220 \\
(61.6)\end{array}$ & 251.5 & 8981 & 3756 & 56.50 & 81.81 & 8.98 & 3.75 \\
\hline Salicylic acid & $\begin{array}{c}189 \\
(55.1)\end{array}$ & $\begin{array}{c}159 \\
(62.2)\end{array}$ & 174 & $\begin{array}{c}309 \\
(46.0)\end{array}$ & $\begin{array}{c}251 \\
(58.1)\end{array}$ & 280 & 9387 & 4468 & 54.53 & 78.38 & 9.38 & 4.46 \\
\hline Selenium & $\begin{array}{c}287 \\
(36.7)\end{array}$ & $\begin{array}{c}239 \\
(43.4)\end{array}$ & 253 & $\begin{array}{c}377 \\
(34.1)\end{array}$ & $\begin{array}{c}354 \\
(38.1)\end{array}$ & 365.5 & 13816 & 12797 & 33.08 & 38.02 & 13.81 & 12.79 \\
\hline Control & \multicolumn{2}{|c|}{422} & - & \multicolumn{2}{|c|}{572} & - & \multicolumn{2}{|c|}{20646} & $\cdot$ & $\cdot$ & \multicolumn{2}{|c|}{20.64} \\
\hline Mean Time & 236.8 & 209.7 & - & 359 & 319.4 & - & - & - & $\cdot$ & $\cdot$ & - & - \\
\hline LDS 0.05 Chemicals (C) & \multicolumn{2}{|c|}{8.43} & \multicolumn{3}{|c|}{9.50} & & & & & & & \\
\hline LDS 0.05 Time $(T)$ & \multicolumn{2}{|c|}{6.84} & \multicolumn{3}{|c|}{11.23} & & & & & & & \\
\hline LDS $0.05 \mathrm{CxT}$ & \multicolumn{2}{|c|}{11.92} & \multicolumn{3}{|c|}{13.44} & & & & & & & \\
\hline
\end{tabular}

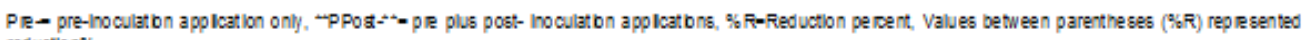
reduction\%. 
Table (5). Effect of pre and post-inoculation application of chemical substances efficacy versus pre-incculation application only on growth parameters of tomato plants infected with $M$. incognila under greenhouse conditions.

\begin{tabular}{|c|c|c|c|c|c|c|c|c|c|c|c|c|c|c|c|}
\hline \multirow{3}{*}{ Chemical substances } & \multicolumn{9}{|c|}{ Shoot } & \multicolumn{6}{|c|}{ Root } \\
\hline & \multicolumn{2}{|c|}{ Fresh weight } & \multirow{2}{*}{$\begin{array}{c}\text { Mean } \\
\text { C }\end{array}$} & \multicolumn{2}{|c|}{ Dry weight } & \multirow{2}{*}{$\begin{array}{c}\text { Mean } \\
\text { C }\end{array}$} & \multicolumn{2}{|c|}{ length } & \multirow{2}{*}{$\begin{array}{c}\text { Mean } \\
\text { C }\end{array}$} & \multicolumn{2}{|c|}{ weight } & \multirow{2}{*}{$\begin{array}{c}\text { Mean } \\
\text { C }\end{array}$} & \multicolumn{2}{|c|}{ length } & \multirow{2}{*}{$\begin{array}{c}\text { Mean } \\
\text { C }\end{array}$} \\
\hline & Pre* & $\begin{array}{c}\text { Pot } \\
\text { Post- }\end{array}$ & & Pre & $\begin{array}{c}\mathbf{P} \\
\text { Post- }\end{array}$ & & Pre- & $\begin{array}{c}\text { P } \\
\text { Post- }\end{array}$ & & Pre- & $\begin{array}{c}\text { P } \\
\text { Post- }\end{array}$ & & Pre- & $\begin{array}{c}\text { P } \\
\text { Post- }\end{array}$ & \\
\hline Acetyl salicylic acid & 30.29 & 37.26 & 33.78 & 4.41 & 5.29 & 4.85 & 43.00 & 48.33 & 44.67 & 10.78 & 13.12 & 11.95 & 33.00 & 35.00 & 34.00 \\
\hline$\beta$-amino butyric acid & 29.22 & 35.04 & 32.13 & 4. 12 & 4.68 & 4.39 & 39.67 & 44.00 & 41.84 & 10.43 & 11.52 & 10.98 & 32.00 & 33.33 & 32.67 \\
\hline Ascorbic acid & 30.34 & 31.91 & 31.13 & 3.38 & 4.05 & 3.72 & 39.00 & 40.33 & 39.67 & 9.13 & 10.37 & 9.75 & 30.33 & 31.00 & 30.67 \\
\hline Chloroisonicotinic acid & 9.94 & 2.04 & 5.99 & 1.34 & 0.58 & 0.96 & 25.67 & 18.00 & 21.84 & 3.79 & 1.78 & 2.79 & 24.00 & 18.33 & 21.17 \\
\hline Chlorosalicylic acid & 25.22 & 30.02 & 27.62 & 3.54 & 4.47 & 4.01 & 41.00 & 44.67 & 42.84 & 10.60 & 12.27 & 11.44 & 31.67 & 34.00 & 32.84 \\
\hline Nitro salicylic acid & 28.98 & 31.46 & 30.22 & 3.87 & 4.56 & 4.22 & 40.33 & 43.00 & 41.67 & 9.36 & 10.44 & 9.90 & 32.67 & 33.00 & 32.84 \\
\hline Salicylic acid & 31.72 & 40.54 & 36.13 & 4.74 & 5.49 & 5.12 & 42.00 & 47.33 & 44.67 & 9.92 & 12.70 & 11.31 & 34.00 & 37.00 & 35.50 \\
\hline Selenium & 33.41 & 32.28 & 32.84 & 3.69 & 3.24 & 3.47 & 41.00 & 38.67 & 39.84 & 9.88 & 9.10 & 9.49 & 31.33 & 30.67 & 31.00 \\
\hline Nematode infected plant & \multicolumn{2}{|c|}{13.49} & - & \multicolumn{2}{|c|}{208} & - & \multicolumn{2}{|c|}{32.00} & - & \multicolumn{2}{|c|}{5.72} & - & \multicolumn{2}{|c|}{28.00} & - \\
\hline Mean Time & 25.85 & 28.22 & - & 3.46 & 3.82 & - & 38.19 & 39.37 & - & 8.85 & 9.67 & - & 30.78 & 31.15 & - \\
\hline LSD 0.05 Chemicals & \multicolumn{2}{|c|}{1.58} & & \multicolumn{2}{|c|}{0.49} & \multicolumn{3}{|c|}{2.42} & & \multicolumn{2}{|c|}{0.83} & \multicolumn{4}{|c|}{2.49} \\
\hline LSD 0.05 Time & \multicolumn{2}{|c|}{2.11} & & \multicolumn{2}{|c|}{0.41} & \multicolumn{3}{|c|}{2.25} & & \multicolumn{2}{|c|}{0.31} & \multicolumn{4}{|c|}{1.94} \\
\hline LSD 0.05 CxT & \multicolumn{2}{|c|}{2.24} & & \multicolumn{2}{|c|}{0.69} & \multicolumn{3}{|c|}{3.42} & & \multicolumn{2}{|c|}{1.17} & \multicolumn{4}{|c|}{3.53} \\
\hline
\end{tabular}

Pre-*= Pre-inoculation application only, $\mathrm{P}-\mathrm{Post}-\mathrm{Pre}$ and post- inoculation application, $\mathrm{C}=$ chemicals. 
Table (6). Effect of some chemical substances on peroxidase and polyphenol oxidase activities in tomato roots infected with $M$. incognita.

\begin{tabular}{lcccc}
\hline \multirow{2}{*}{\multicolumn{1}{c}{ Chemical substances }} & \multicolumn{4}{c}{ Enzymes } \\
\cline { 2 - 5 } & Activity & $\begin{array}{c}\text { Relative } \\
\text { activity }\end{array}$ & Activity & $\begin{array}{c}\text { Relative } \\
\text { activity }\end{array}$ \\
\cline { 2 - 5 } Acetyl salicylic acid & 1.155 & 342.08 & 1.102 & 1033.01 \\
$\boldsymbol{\beta}$-aminobutyric acid & 2.248 & 665.75 & 1.529 & 1432.89 \\
Ascorbic acid & 1.057 & 313.14 & 0.658 & 616.47 \\
Chloroisonicotinic acid & 1.262 & 373.66 & 1.138 & 1066.33 \\
Chlorosalicylic acid & 2.916 & 863.10 & 2.027 & 1899.41 \\
Nitro salicylic acid & 2.533 & 749.95 & 1.804 & 1691.14 \\
Salicylic acid & 1.662 & 492.07 & 1.209 & 1132.98 \\
Selenium & 0.898 & 265.77 & 0.560 & 524.84 \\
Healthy (Uninfected untreated) & 0.338 & 100.00 & 0.107 & 100.00 \\
Check (Infected untreated) & 0.782 & 231.56 & 0.204 & 191.61 \\
\hline LDS 0.05 & $\mathbf{0 . 2 1}$ & & $\mathbf{0 . 3 9}$ & \\
\hline
\end{tabular}

\section{Discussion}

The previous results demonstrate that the pre-inoculation addition of chemicals is more effective than the post-inoculation. These results are in accordance with Arrigoni et al., (1979); Al-Sayed, (1992) and Nandi et al., (2000), (2002\& 2003). In 2005 Pandey and Kalra showed that ASA, INA, NSA, CSA, SA and isonicotinamide applied as pre-infection could suppress nematode reproduction. Also, Sanz et al., (2008) found a reduction in galls in relation to the application of INA and SA to tomato two days before infection with $M$. incognita. Molinari and Baser (2010) confirmed these results and mentioned that the effect of the pre-inoculation indicates the persistence of defense elicitation by a determined systemic resistance acquired (SRA) effect for a long time. Possible mechanism explaining the efficacy of pre-inoculation treatment of chemical inducers was supposed by Cohen and Gisi (1994) they mentioned that BABA is not metabolized in tomato plants; it is thought to bind to cell-wall proteins, resulting in cell walls that are resistant to infection. They added another possible mechanism of resistance may result from synthesis in tomato roots of compounds with deleterious effects on nematode and giant sell development. Nematodes may ingest BABA directly through the giant cells, which would then interfere with normal amino acid and protein synthesis by the nematodes. It is evident that BABA has been found in tomato root exudates, Gamliel and Katan (1993). 
Dichloroisonicotinic acid (INA) has been shown to induce disease resistance in a number of plants including green bean (Dann and Deverall, 1995) against a broad range of pathogens. In addition to, Dann et al., (1998) suggested that INA treatment may stimulate inherent defense mechanisms so plant can respond more quickly against infection. INA provided as soil-drench at concentrations lower than that used here did reduce egg-masses and nematode reproduction, although with negative effects on plant fitness these finding are in agreement with Chinnasri et al., (2006). Salicylic acid (SA) is an endogenous signal for the activation of certain plant defense responses by expression of genes for pathogenesis-related protein (PR-1) and enhanced resistance to pathogens. SA, in particular, has a biotic role in nematode susceptible plants and it has been regarded as resistance inducer (Nandi et al., 2003, Osman et al., 2012 and Zinovieva et al., 2013).

The effect of repeating dose after nematode inoculation on activation of chemical inducers efficacy was obvious in our results and are in agreement with Oka et al., (1999). They demonstrated that addition of BABA reduced the number of $M$. javanica eggs and galls on infected tomato roots. They also found that two doses after inoculation with nematode was better than one dose and near to three doses and the differences between two or three doses were not significantly different. Also in 2010 Molinari and Baser indicated that the efficacy of activators in eliciting resistance to root-knot nematode is strictly dependent on the amount applied which in turn determines the amount of chemicals adsorbed by the plants. Although depending on the amount of chemical provided, root adsorption may be influenced by an array of factors, such as the method of application, the age and health of the adsorbing plants and the environmental conditions.

Plant growth was positively reacted in general due to addition chemicals when used in proper dose; these data are compatible with those of Molinari (2008). $\mathrm{He}$ has shown that appropriate doses of SA provided to well-developed tomato plants may markedly reduce root-knot nematodes infestation and reproduction with no negative effects on plant fitness. It is likely that SA inhibit the penetration and/or the establishment of the feeding sites by the invading juveniles, thus encouragement in plant growth criteria occur. Repeating application of certain chemical was not always benefit for plant growth, these may due to their effect on plant physiological processes and metabolism, which became pronounced as concentrations elevated inside plant cell sap. On the other hand, some chemical can accumulated in plant tissues caused phytotoxic effect or rendering growth. Unfortunately, INA was phytotoxic to tomato and the toxicity increased by increasing the amounts added to roots. These findings are similar to recorded by (Molinari and Baser, 2010). Selenium may be accumulated in plants resulting toxicity when reached to such level which interfered with plant metabolic activity.

Phytotoxicity caused by the application of some SAR inducers has been increasingly documented. The mechanism responsible for the reduced plant fitness 
associated with SAR induction is not known (Cipollini et al., 2003), although resource allocation tradeoff has been widely supported as a key mechanism. Baldwin et al., (1998) found that induced responses caused an increase in nicotine content, which is a putative defense compound. In addition, Baldwin and Callahan (1993) found that high levels of nicotine lead to autotoxicity to plants. Recent experiments utilizing differential display or microarrays to analyze gene expression have shown that induced plant responses are associated with the coordinate upregulation of many defense-related transcripts and the down regulation of transcripts involved in primary metabolism (Reymond et al., 2000 and Hermsmeier et al., 2001). These findings support the assumption that upon induction, resources are allocated toward defense and away from primary metabolism, leading to fitness costs in the plant.

Many authors stated that pre and post infection application of chemical inducer were more effective than pre infection application only (Oka et al., 1999 and Mutar \& Fattah, 2013). They added that plants treated with BABA render roots less attractive to Meloidogyne juveniles through altered plant nutrient assimilation or render plant cell walls harder to penetrate by $\mathrm{J}_{2}$ which caused the formation of smaller giant cells which are not able to provide enough nutrients for the developing nematodes. In addition to, Dann, et al., (1998) suggested that INA treatment may stimulate inherent defense mechanisms so plant can respond more quickly against infection. The promised results which gained by the combination of pre and post inoculation application may be due to increasing the amount of chemical provided, so when the chemical inducer is abundance within plant the induction resistance is extended to adversely affected nematode development, as well as enhance plant growth.

Activation POX and PPO is a general response of infected plants tissue and its leaves have been correlated with resistance (Sridhar and Ou, 1974). In another study, Kataria et al., (1997) found that pretreated of bean seedling with NSA, ASA and INA acquired a high level of POX activity. Mostafa and Youssef, (2007) stated that ethyl salicylic and jasmonic acid increased the POX activity. In particular POX activity has been reported to be biochemical marker for resistance and to be associated with systemic resistance (Mosa, 2002 and Nawar \& Kuti, 2003). Using some chemical compounds like SA and AS showed increasing in POX and PPO activity (Saeed, 2005).

Thus, the measurement of POX and PPO activities may provide a convenient method for screening and quantification of inducers activity. Moreover, it is evident that enzymes in host plants play an important role in the mechanisms of resistance to nematodes, in other words nematode infection enhanced enzyme activity. Induction of Mi-mediated nematode resistance is correlated with increased activity of several enzymes implicated in defense; POX and PPO (Zacheo et al., 1993). So, the increasing of these enzymes are an active response in systemic induce 
resistance (Irving and Kuc, 1990).

In conclusion: SAR inducers differed in their ability to reduce nematode reproduction on tomato, while CSA, NSA, BABA, and SA are among the most potent SAR inducers. Differential potency among SAR inducers and between nematode species may be due to different activation points along the signal transduction pathway of SAR. Also, chemical activators which correctly applied at the most effective dosages can be used for nematode management in conventional and organic tomato protected cultivation, better if included in integrated management programs. Further investigations are needed to verify whether such SAR elicitors may be effective in limiting nematode infestation to other crops, or whether their application may be feasible also in field conditions. On the other hand, INA was found to have phytotoxic effects than the other SAR elicitors used and, therefore, a lower dosage was applied to plants for induction of resistance.

\section{References}

Al-Sayed, A.A. (1992). Effect of ascorbic acid and L-arginine on controlling Meloidogyne incognita as influenced by soil temperature. Annals of Agricultural Science, Moshtohor 30(3): 1549-1558.

Amin, A.W. (1994). The root-knot nematodes (Meloidogyne species) in Hungary. Bulletin EPPO/OEPP, 24(2): 417-422.

Amin, A.W. and Abd-EL Wanis Mona (2014). Protecting from cucumber Meloidogyne incognita using graft onto resistant cucurbit rootstocks and antagonistic marigold as an alternative to nematicide. Pakistan Journal of Nematology, 32(1): 51-58

Arrigoni, O.; G. Zacheo; R. Arrigoni-Liso; T. Bleve-Zacheo and F. Lamberti (1979). Relationship between ascorbic acid and resistance in tomato plants to Meloidogyne incognita. Phytopathology, 69 (6): 579-581.

Baldwin, I.T. and P. Callahan (1993). Autotoxicity and chemical defense: Nicotine accumulation and carbon gain in solanaceous plants. Oecologia, (94): 534541.

Baldwin, I.T.; D. Gorham; E.A. Schmelz; C.A. Lewandowski and G.Y. Lynds (1998). Allocation of nitrogen to an inducible defense and seed production in Nicotian aattenuata. Oecologia, (115):541-552.

Baysal, O.; E.M. Soylu and S. Soylu (2003). Induction of defence-relatedenzymes and resistance by the plant activator acibenzolar- S-methyl in tomato seedlings against bacterial canker caused by Clavibacter michiganensis ssp. michiganensis. Plant Pathol., (52):747-753. 
Bonaldo, S.M.; S.F. Pascholati and R.S. Romeiro (2005). Indução de resistência: noçõesbásicas e perspectivas. In: Cavalcanti LS, Di Piero RM, Cia P, Pascholati SF, Resende MLV, Romeiro RS (eds) Indução de resistênciaemplantas a patógenos e insetos. Piracicaba: FEALQ, pp. 11-28.

Chinnasri, B.; B.S. Sipes and D.P. Schmitt (2006). Effects of Inducers of Systemic Acquired Resistance on Reproduction of Meloidogyne javanica and Rotylenchulus reniformis in Pineapple. J. Nematology, 38(3):319-325.

Cipollini, D.; C.B. Purrington and J. Bergelson (2003). Costs of induced responses in plants. Basic and Appl. Ecology, (4):79-85.

Cohen, Y., and U. Gisi, (1994). Systemic translocation of 14C-DL-3-aminobutyric acid in tomato plants in relation to induced resistance against Phytophthora infestans. Physiol. Mol. Plant Pathol., (45): 441-456.

Dann, E.; B. Diers; J. Byrum and R. Hammerschmidt (1998). Effect of treating soybean with 2,6dichloroisonicotinic acid (INA) and benzothiadiazole (BTH) on seed yields and the level of disease caused by Sclerotiniasclerotiorum in field and greenhouse studies. Euro.J. P. Path., (104): 271-278.

Dann, E.K. and B.J. Deverall (1995). Effectiveness of systemic resistance in bean against foliar and soil borne pathogens as induced by biological and chemical means. Plant Path., (44): 458-466.

Dias-Arieira, C.R.; Marini P.M.; Fontana L.F.; M. Roldi and T.R.B. Silva (2012). Effect of Azospirillum brasilense, Stimulate $\AA^{\circledR}$ and potassium phosphate to control Pratylenchus brachyurus in soybean and maize. Nematropica, (42):170-175.

Franzener, G.; A.S. Martinez-Franzener; J.R. Stangarlin; C. Furlanetto and Schwan-Estrada K.R.F. (2007). Proteção de tomateiro a Meloidogyne incognita peloextratoaquoso de Tagetespatula. Nematol. Bras., (31):27-36.

Gamliel, A. and J. Katan (1993). Suppression of major and minor pathogens by fluorescent pseudomonads in solarized and nonsolarized soils. Phytopathology, (83): 68-75.

Ghini, R. and H. Kimati (2000). Resistência de fungos a fungicidas.Jaguariúna, São Paulo: Embrapa MeioAmbiente. P. 78.

Hermsmeier, D.; U. Schittko and I.T. Baldwin (2001). Molecular interactions between the specialist herbivore Manducasexta(Lepidoptera, Sphingidae) and its natural host Nicotiana attenuata. I. Largescale changes in the accumulation of growth and defense-related plant mRNAs. Plant Physiol. (125): 683-700. 
Irving, H.R. and J. Kuć (1990). Local and systemic induction of peroxidase, chitinase and resistance in cucumber plants by $\mathrm{K}_{2} \mathrm{HPO}_{4}$. Physiology of plant pathology., (37): 355-366.

Kataria, H.R.; B. Wilmsmeier and H. Buchenaure (1997). Efficacy of resistance inducers, free radical scavengers and an antagonistic strain of Pseudomonas fluorescens for control of Rhizoctoniasolani AG-4 in bean and cucumber. Plant path., (46): 897-909.

Maxwell, D.P. and F.D. Bateman (1967). Changes in the activities of some oxidases in extract of Rhizoctonia- infected bean hypocotyls in relation to lesion maturation. Phytopath., (57): 132.

Molinari, S. (2008). Salicylic acid acts as a resistance elicitor on tomato seedlings attacked by root-knot nematodes: effect of plant age. Redia XCI, 73-75.

Molinari, S. and N. Baser (2010). Induction of resistance to root-knot nematodes by SAR elicitors in tomato. Crop Prot., (29):1354-1362.

Mosa, A.A. (2002). Induced resistance in rice against blast disease using abiotic and biotic agents. Ann. Agric. Sci. Ain shams Univ. Cairo. (47): 933-1008.

Mostafa, M.H.; E.A.M. Gado and M.M. Youssef (2007). Induction of resistance in tomato plats against root-knot nematode by some chemical and plants extracts (2007). Arab Univ. J.Agric. Sci., Ain Shams Univ., Cairo, 15(1), 177-184.

Mutar, S.S. and F.A. Fattah (2013). Induced Systemic Resistance in Tomato Plants against Meloidogyne spp by Seed Treatment with $\beta$, Amino Butyric Acid and Benzothiadiazol. Journal of Biology, Agriculture and Healthcare, 3(12): 110-114

Nandi, B., Kundu, K., Banerjee, N. and Babu, S.P.S. (2003). Salicylic acid induced suppression of Meloidogyne incognita infestation of okra and cowpea. Nematology, (5): 747-752.

Nandi, B., Sukul, N.C., Banerjee, N. and Babu, S.P.S. (2000). Salicylic acid reduces Meloidogyne infestation of cowpea. Proceedings of Zoological Society, (53): 93-95.

Nandi, B., Sukul, N.C., Banerjee, N., Sengupta, S., Das, P. and Babu, S.P.S. (2002). Salicylic acid enhances resistance in cowpea against Meloidogyne incognita. Phytopathology Mediterranea, (41): 39-44.

Nandi, B.; K. Kundu; N. Banerjee and S.P. SinhaBabu (2003). Salicylic acidinduced suppression of Meloidogyne incognita of okra and cowpea. Nematology, (5): 747-752. 
Nawar, H.F. and J.O. Kuti (2003). Wyerone Acid Phytoalexin Synthesis and Peroxidase Activity as Markers for Resistance of Broad Beans to Chocolate Spot Disease. Phytopathology, (151): 564-570.

Oka, Y.; H. Koltai; M. Bar-Eyal; M. Mor; E. Sharon; I. Chet and Y. Spiegel (2000). New strategies for the control of plant-parasitic nematodes.Pest Manag. Sci., (56): 983-988.

Oka, Y.; Y. Cohen and Y. Spiegel (1999). Local and systemic induced resistance to the root-knot nematode in tomato by DL-b-amino-nbutyric acid. Phythopathology, (89):1138-1143.

Osman, H.A.; M.M.A. Youssef; A.Y. El-gindi; H.H. Ameen; N.A. Abd-Elbary and A.M.S. Lashein (2012). Effect of salicylic acid and Pseudomonas fluorescens against Meloidogyne incognita in eggplant using split-root technique. Pak. J. Nematol., 30 (2): 101-113.

Reymond, P.; H. Weber; M. Damond and E.E. Farmer (2000). Differential gene expression in response to mechanical wounding and insect feeding in Arabidopsis. Plant Cell, (12):707-719.

Saeed, M.R.M. (2005). Utilization of some specific materials to stimulated resistance in some host plants against the root-knot nematodes.PhD thesis. Fac. Agric. Cairo Univ.

Sanz, A, S.; B. Mateos; R. Alvarado and M. Sánchez (2008). SAR induction in tomato plants is not effective against root-knot nematode infection. Eur. J. Plant Pathol., (120): 417-425.

Silva, L.H.C.P.; J.R. Campos; M.R. Dutra and V.P. Campos (2004). Aumento da resistência de cultivares de tomate a Meloidogyne incognita com aplicação de acibenzolar-S-meltil. Nematol. Bras., (28):199-206.

Sridhar, R. and S.H. Ou (1974). Biochemical changes associated with development of resistant and susceptible types of rice blast lesion. Phytopathol. Z., (79): 222-230.

Starr, J.L. and P.A. Roberts (2004). Resistance to plant-parasitic nematodes. In: Chen, Z.X., Chen, S.Y., Dickson, D.W. (Eds.), Nematology: Advances and Perspectives. CAB International, Wallingford, UK, pp. 879-907.

Zacheo, G.; C. Orlando and T. Bleve-Zacheo (1993). Characterization of Anionic Peroxidases in Tomato Isolines Infected by Meloidogyne incognita, J. of Nematology, 25 (2): 249-256.

Zinovieva, S.V.; N.I. Vasyukova; Z.V. Udalova and N.G. Gerasimova (2013). The Participation of salicylic and jasmonic acids in genetic and induced resistance of tomato to Meloidogyne incognita. Biology Bulletin, (40): 297303. 


\section{الملخص العببي}

تقييم بعض المواد الكيماوية كمستحثات لمقاومة نباتات الطماطم ضد نيماتودا تعقد الجذور

(ميلودوجيني انكوجنيتا)

السيد عبد الغني عنتر*، أمين وفدي أمين*، عزة هاشم عشوب*** وأحمد سليمان النوبي

* قسم الحيوان و النيماتولوجيا الزراعية-كلية الزراعة- جامعة القاهرة

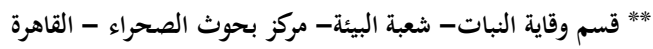

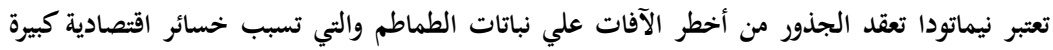

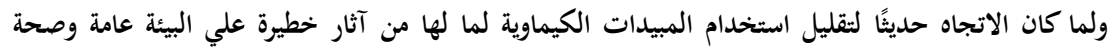

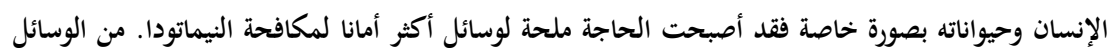

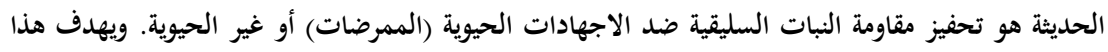

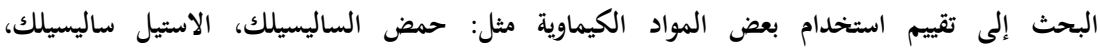

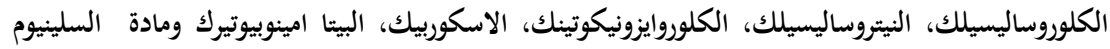

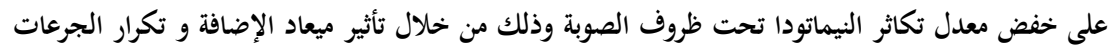

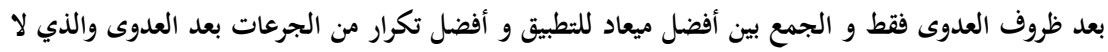
يؤثر سلبًا على صحة النباتات.

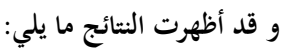

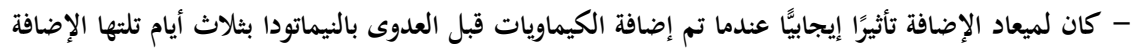

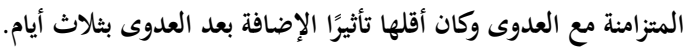

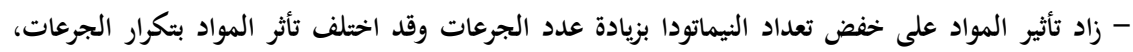

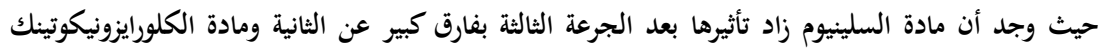

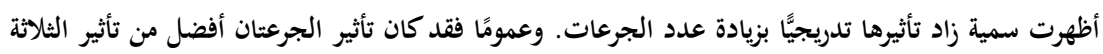

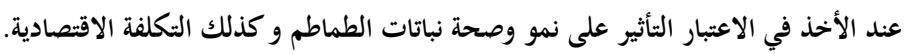

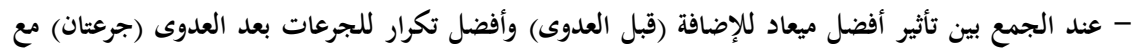

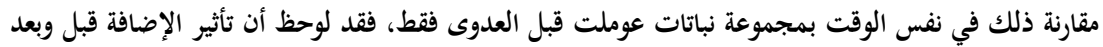

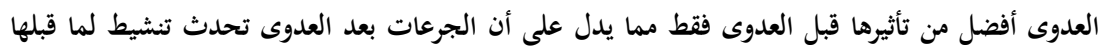
وتتداخل سلبيَّا مع نمو و تطور النيماتودا.

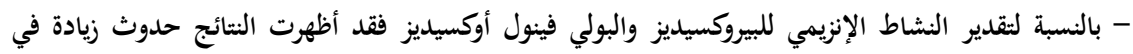

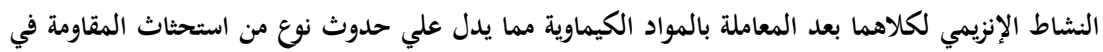
نبات الطماطم وقد ارتبط هذا بانخفاض في تعداد النيماتودا.

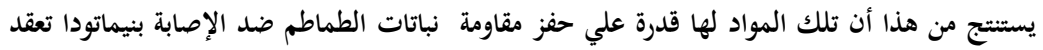

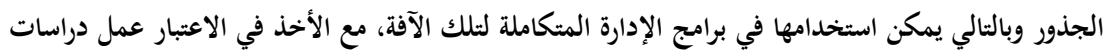

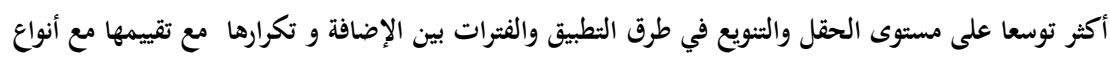
نباتية أخرى كل هذا مع مراقبة للحالة الصحية للنباتات لتعظيم الاستفادة من استخدام تلك الكئ المواد. 